\title{
Testing Small CPAS Parachutes Using HIVAS
}

\author{
Eric S. Ray ${ }^{1}$ \\ Jacobs Engineering, Houston, TX, 77058 \\ Elsa Hennings ${ }^{2}$ \\ Naval Air Warfare Center Weapons Division, China Lake, CA 93555 \\ Michael A. Bernatovich ${ }^{3}$ \\ NASA Johnson Space Center, Houston, TX 77058
}

The High Velocity Airflow System (HIVAS) facility at the Naval Air Warfare Center (NAWC) at China Lake was successfully used as an alternative to flight test to determine parachute drag performance of two small Capsule Parachute Assembly System (CPAS) canopies. A similar parachute with known performance was also tested as a control. Realtime computations of drag coefficient were unrealistically low. This is because HIVAS produces a non-uniform flow which rapidly decays from a high central core flow. Additional calibration runs were performed to characterize this flow assuming radial symmetry from the centerline. The flow field was used to post-process effective flow velocities at each throttle setting and parachute diameter using the definition of the momentum flux factor. Because one parachute had significant oscillations, additional calculations were required to estimate the projected flow at off-axis angles. The resulting drag data from HIVAS compared favorably to previously estimated parachute performance based on scaled data from analogous CPAS parachutes. The data will improve drag area distributions in the next version of the CPAS Model Memo.

\section{Nomenclature}

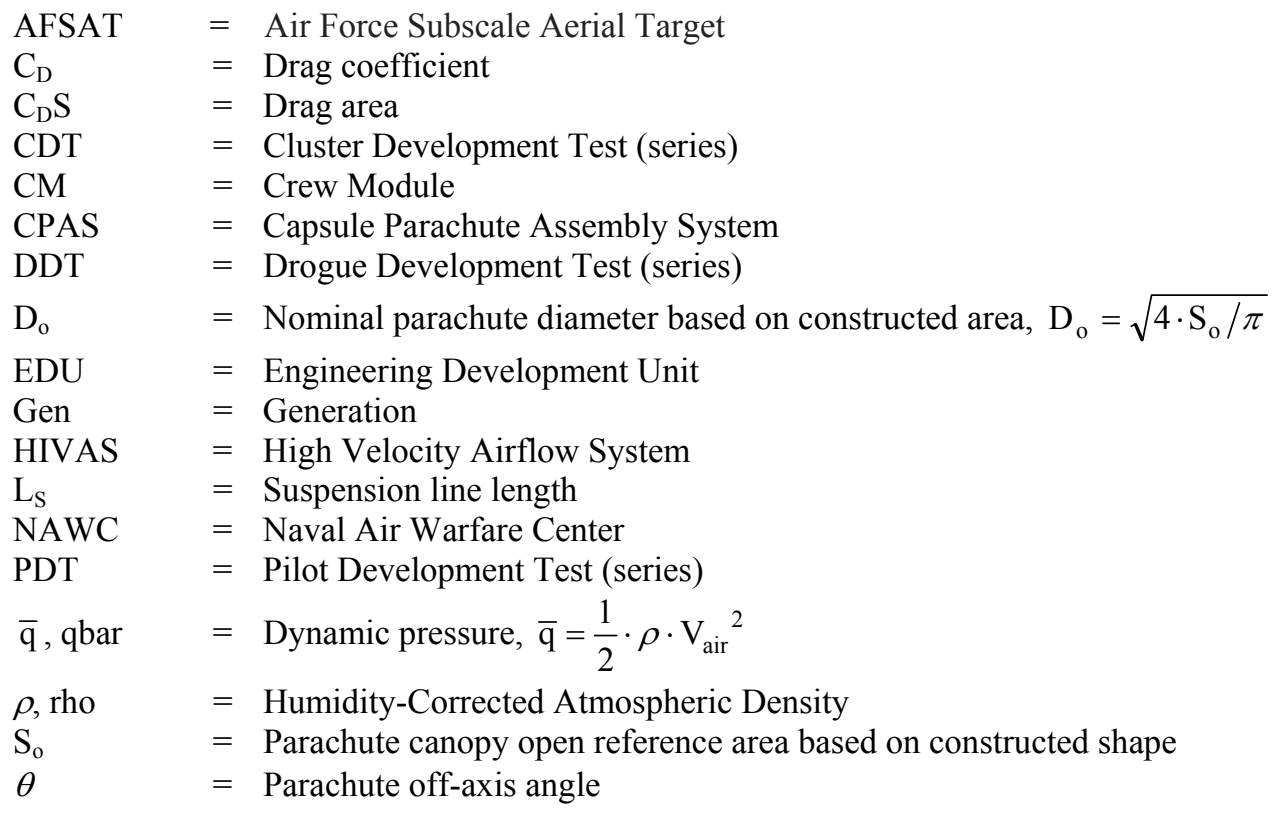

\footnotetext{
${ }^{1}$ Analysis Engineer, Aeroscience and Flight Dynamics, 2224 Bay Area Blvd, Houston, TX, AIAA Member.

${ }^{2}$ Recovery Systems Design Engineer, Human Systems Department, Code 466100D, AIAA Member.

${ }^{3}$ CPAS Analysis Lead, MC DM4, 2101 NASA Parkway, Houston, TX, AIAA Member.
} 
$\begin{array}{ll}\mathrm{u} & =\text { Local flow velocity } \\ \mathrm{V}_{\mathrm{air}} & =\text { Total airspeed relative to air mass }\end{array}$

\section{Introduction}

$\mathrm{O}$ NE of the challenges in the development of the Capsule Parachute Assembly System (CPAS) is testing an evolving design with a limited budget. Building on two previous generations of testing, CPAS is currently conducting Engineering Design Unit (EDU) tests with the full Orion architecture as shown in Figure 1. The EDU flight test series has successfully obtained data from instrumented Drogue and Main parachutes. However, the available test techniques ${ }^{1}$ are limited in altitude, making it difficult to test the Forward Bay Cover Parachutes (FBCPs) in flight-like conditions. While the mortar-deployed Pilot parachutes have been demonstrated during Cluster Development Tests (CDTs), instrumentation to obtain quantitative data has only achieved limited results. Further, CPAS cannot use data obtained from first generation (Gen I) Pilot Development Test (PDT) series ${ }^{2}$ because the design changed from a ringslot to a conical ribbon. Pilot parachutes were not used during Gen II testing.

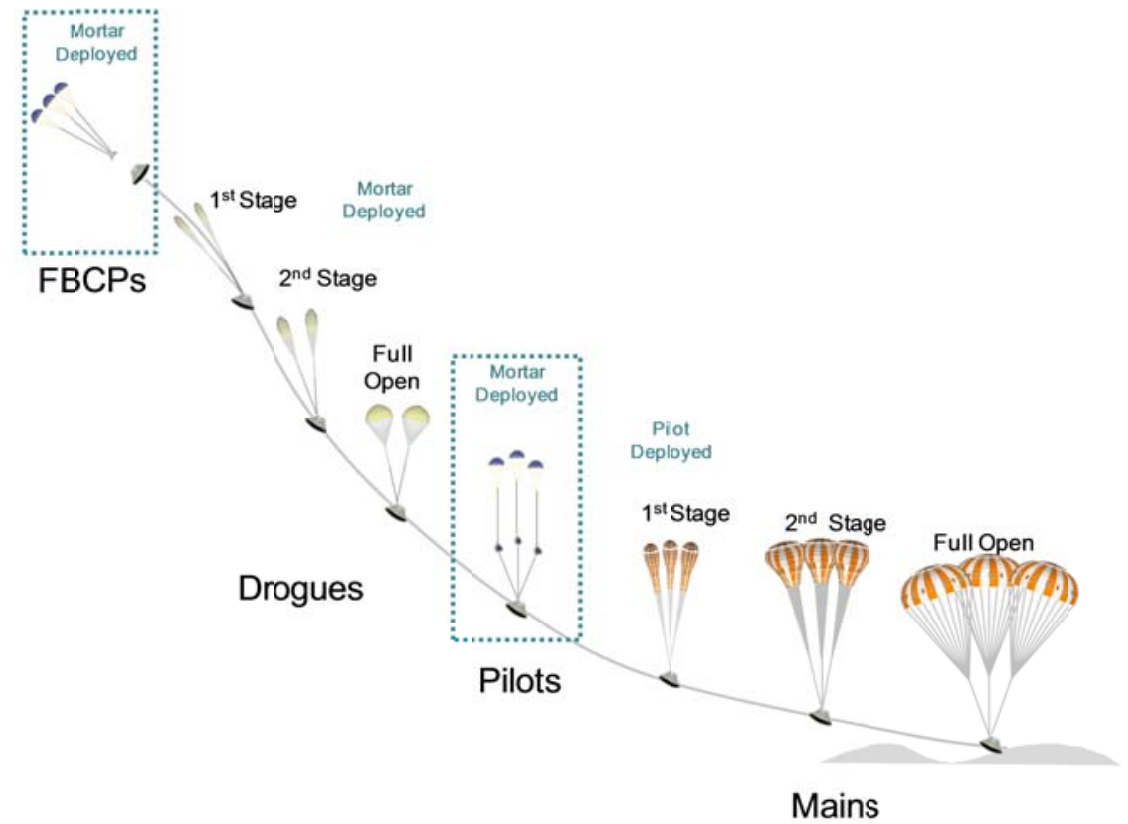

Figure 1. Orion parachute deployment sequence. This paper will focus on the highlighted parachutes.

The High Velocity Airflow System (HIVAS) at the Naval Air Warfare Center (NAWC) at China Lake, California provides a less expensive alternative to test steady-state parachute performance than flight testing. The concept is to create a high-speed flow with a series of TF-33 P11 engines ducted together. There are two HIVAS assemblies at NAWC China Lake. This test used the assembly with four engines, as shown in Figure 2. This same unit was used to test a candidate drogue system for the X-37 approach and landing test vehicle (ALTV). ${ }^{3,45}$ HIVAS allows using the full scale hardware while a wind tunnel would require either a large cross section (and therefore expensive run time) or using subscale models with inherent differences in stiffness and resolution. However, because the deployment is not representative of flight, inflation parameters cannot be determined from HIVAS. 
Because of the low HIVAS test cost, CPAS decided to utilize the facility to test both FBCP and Pilot parachutes. In addition, an Air Force Subscale Aerial Target (AFSAT) Drogue parachute was tested as a control because it has known performance. ${ }^{6}$ All three parachutes are manufactured by Airborne Systems North America.

\section{Test Procedure}

The test was intended to measure parachute performance at a series of desired dynamic pressures. To measure the development of flow velocity, $\mathrm{V}_{\text {air }}$, a flow sensor is located just past the HIVAS nozzle exit, and a flow sensor is located at the approximate location where the specimen parachute will be when inflated as shown in the top section of Figure 3. These velocities are converted to dynamic pressure according to Eq. 1, where $\rho$ is the ambient density.

$$
\overline{\mathrm{q}}=\frac{1}{2} \cdot \rho \cdot \mathrm{V}_{\text {air }}^{2}
$$

The flow sensor at the specimen location must be removed when the parachute is installed as shown in the bottom section of Figure 3. In order to achieve the desired flow at the parachute, the nozzle flow reading is mapped to specimen flow readings via calibration runs. During each calibration run, the HIVAS throttle is adjusted until the specimen sensor reads each desired dynamic pressure. At each setting, the corresponding nozzle dynamic pressure reading is noted. When the test parachute is installed, the previously-determined nozzle readings are dialed-in to provide the desired flow at the specimen. Calibration runs were performed before and between each parachute installation, to account for deviations from the nominal. Ambient atmospheric readings are also recorded, to compensate for the rapid heating of the desert environment.

\section{Calibration Configuration}

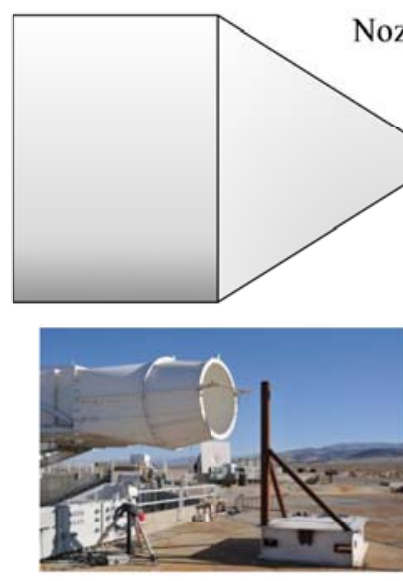

\section{ozzle Flow sensor}

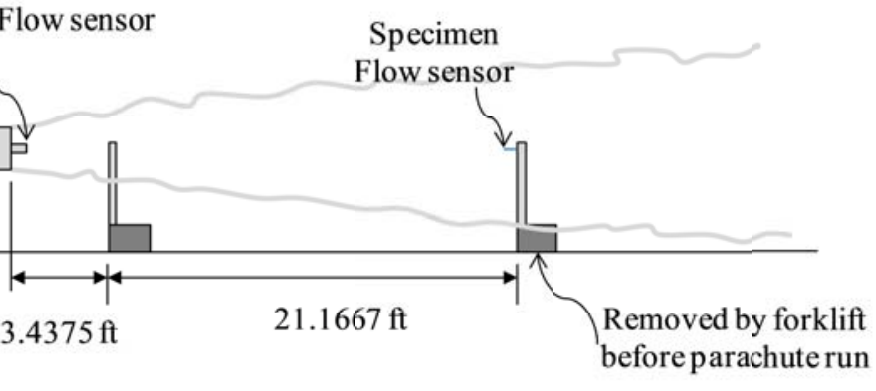

$\underline{\text { Test Configuration }}$

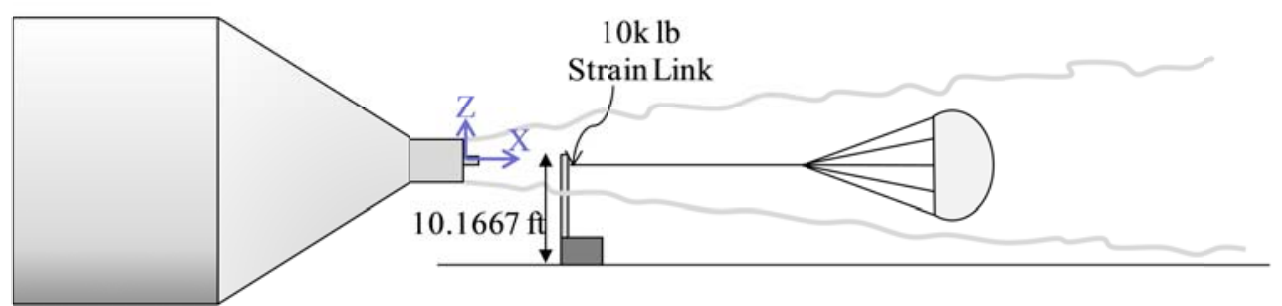

Figure 3. The flow is calibrated with a flow sensor (top). The block with the sensor is removed when the parachute is attached to a strain link (bottom).

Velocity and dynamic pressure histories of the nozzle and specimen from the first calibration run are shown in Figure 4. 

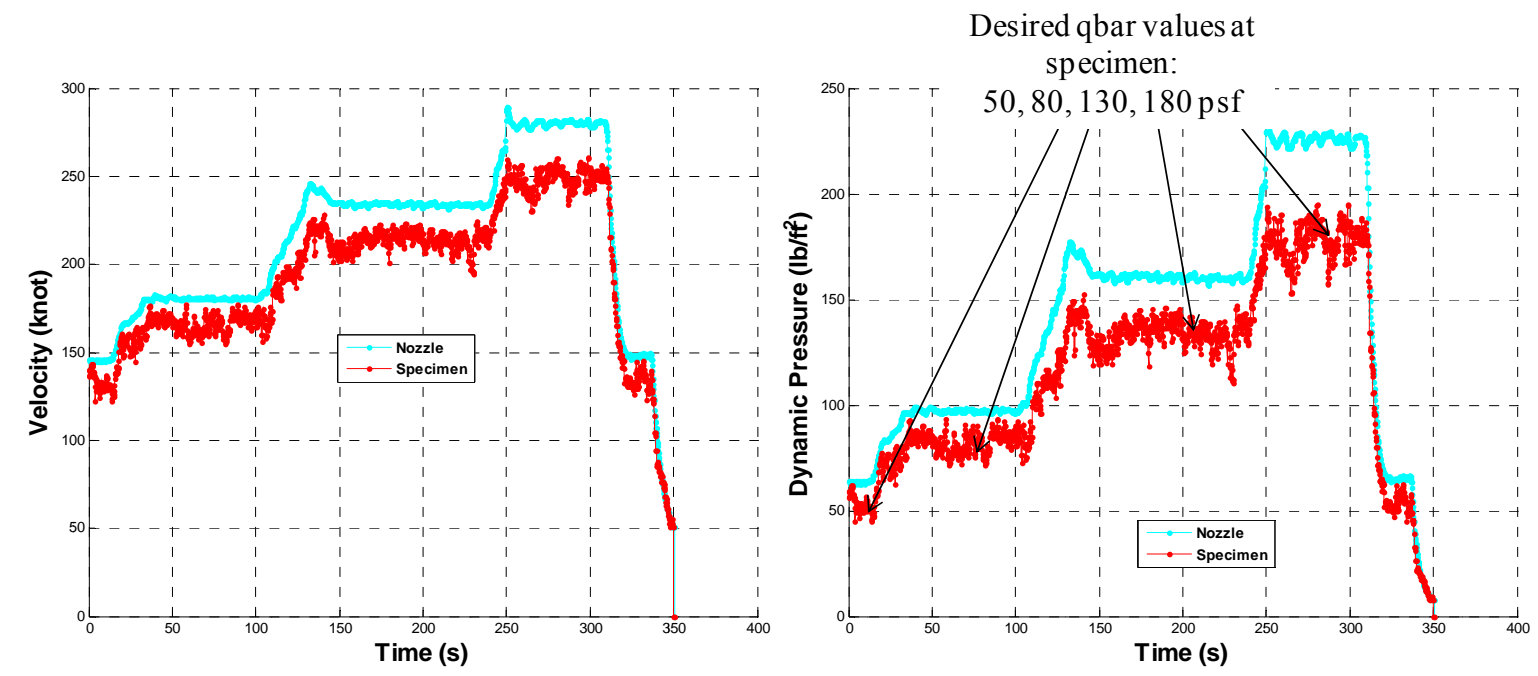

Figure 4. Measured velocity (left) and dynamic pressure (right) at nozzle and specimen.

Because the flow is non-uniform, additional calibration runs were performed at locations approximately along the skirt of each parachute, shown in Figure 5. The ratio of projected diameter to reference diameter, $\mathrm{D}_{\mathrm{p}} / \mathrm{D}_{\mathrm{o}}$, was assumed to be 0.70 based on Table 5-2 of Ref. 7. Later analysis of photographs confirmed this result. Two of the flow surveys were inadvertently performed about one foot below the nozzle centerline, but this oversight was minimized by assuming flow is proportional to the radial distance from the centerline for analysis.

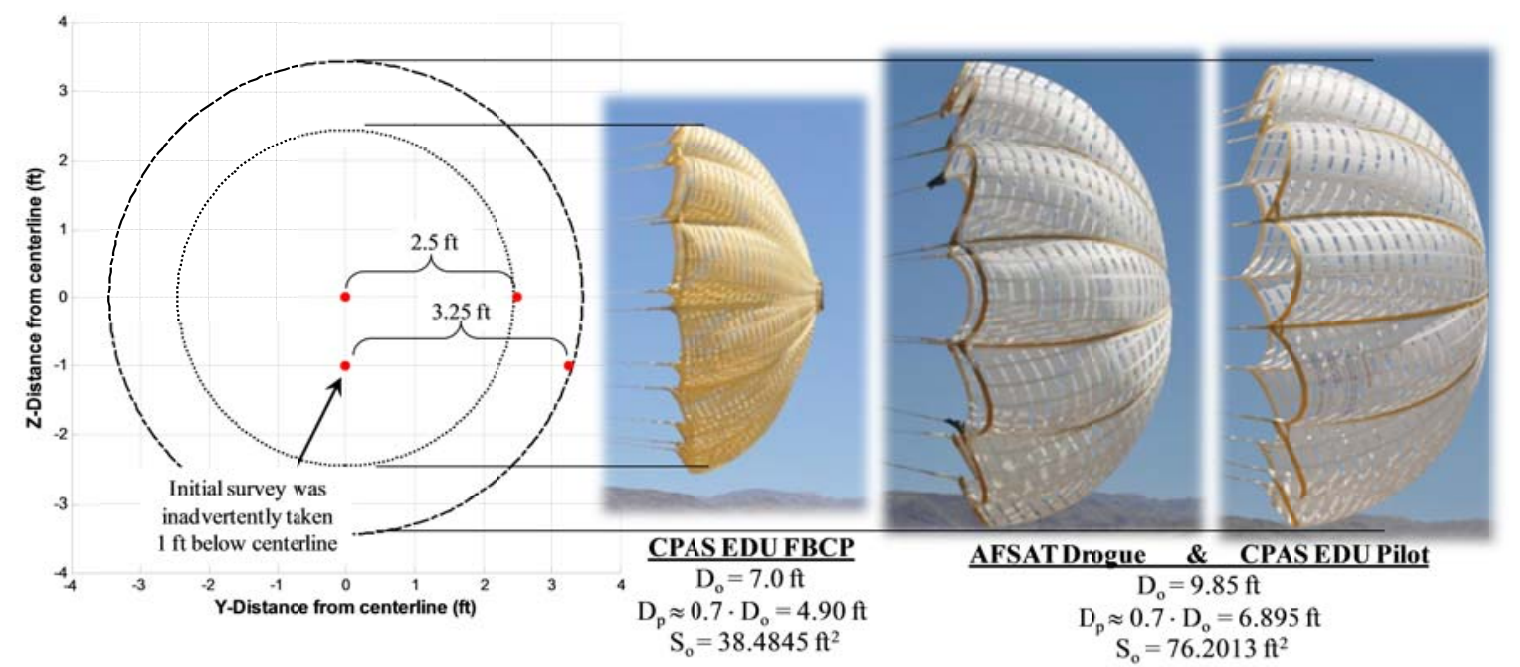

Figure 5. The flow survey locations were intended to be along the centerline and skirt edges. The initial survey was inadvertently about $1 \mathrm{ft}$ below the centerline.

The assumption of radial symmetry allows for polynomials to be fit to the four calibration points. A second order polynomial curve fit was used to characterize the local flow, $u$, as a function of radius, $r$. The dynamic pressure and velocity profiles are plotted in Figure 6. 

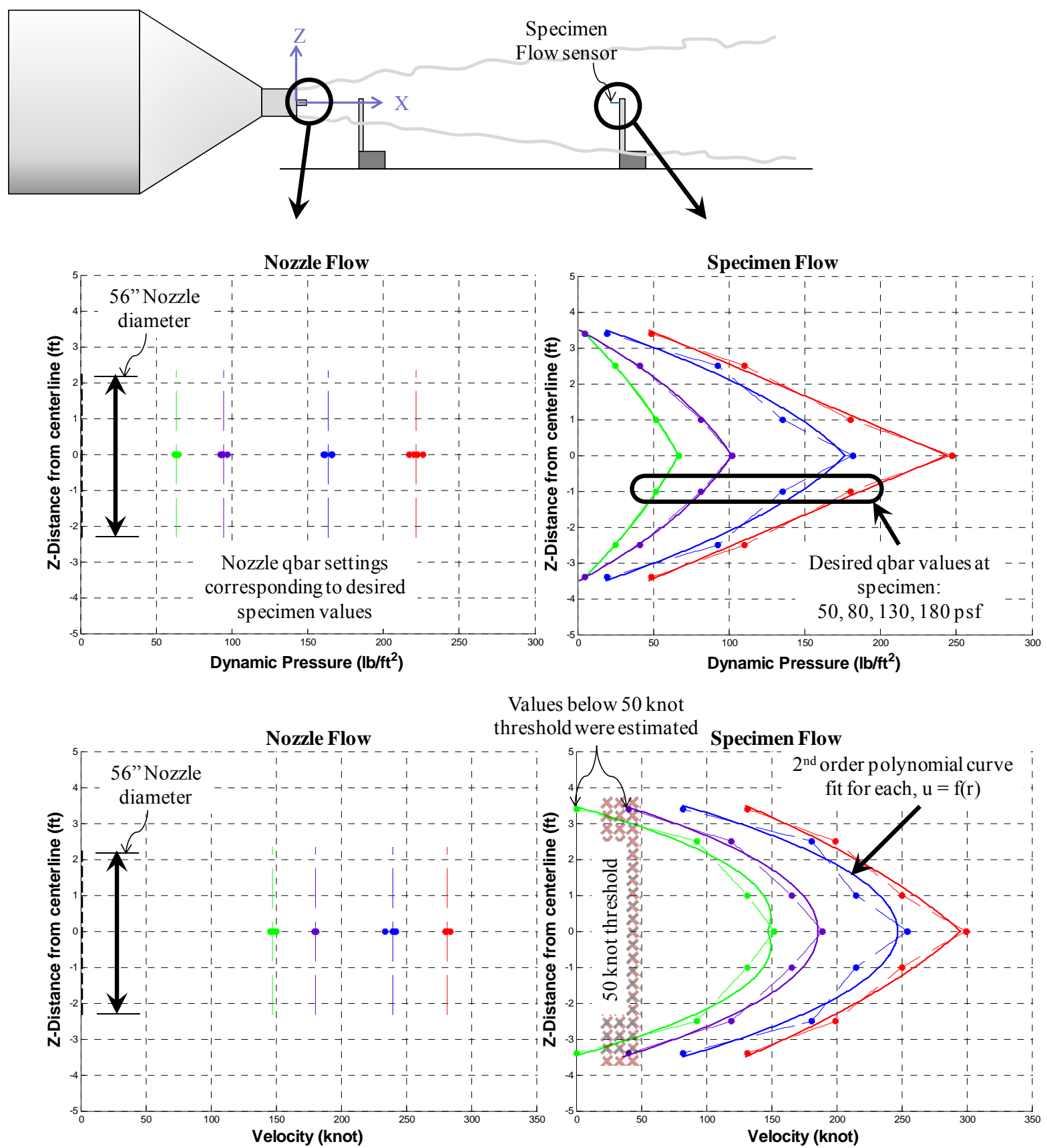

Figure 6. Dynamic pressure and velocity settings at the nozzle exit (left) and corresponding profiles at parachute location (right).

\section{Momentum Flux Correction Factor}

Parachute performance is measured as drag coefficient where the measured force, F, is normalized by the dynamic pressure and reference area, $\mathrm{S}_{0}$, as in Eq. 2 . 


$$
\mathrm{C}_{\mathrm{D}}=\frac{\mathrm{F}}{\frac{1}{2} \cdot \rho \cdot \mathrm{V}_{\mathrm{air}}^{2} \cdot \mathrm{S}_{\mathrm{o}}}
$$

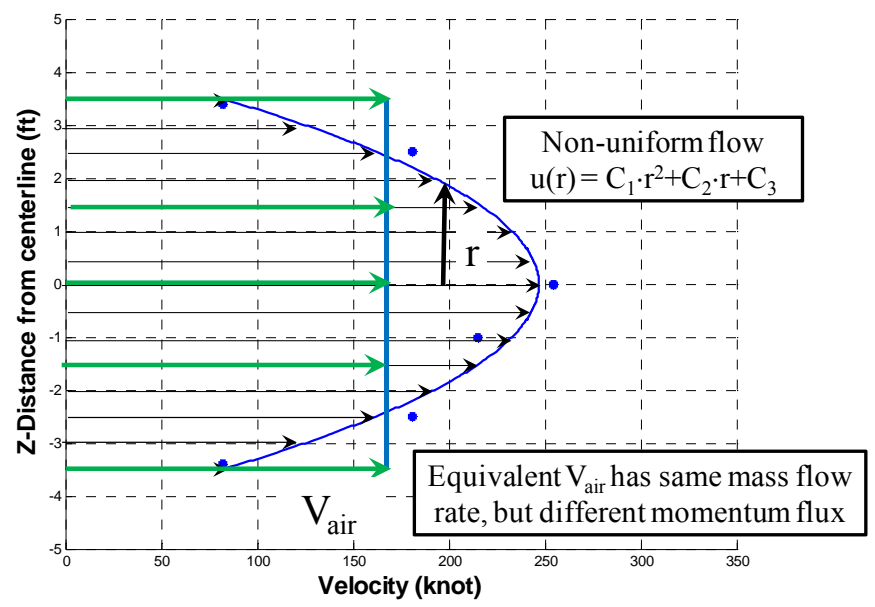

Figure 7. Non-uniform flow and equivalent flow velocity.
However, because the measured flow velocity is non-uniform, the $\mathrm{V}_{\text {air }}$ term must be computed over the given parachute inlet area. The equivalent $\mathrm{V}_{\text {air }}$ will have the same mass flow rate, but a lower momentum flux than the actual non-uniform flow. A momentum flux correction factor, $\beta$, allows the use of an equivalent velocity corresponding to the given mass flow rate. The factor is defined as areaaveraged integral of the square of the normalized local flow velocity, according to Eq. 3. ${ }^{8}$ Therefore, the correction factor needs to be computed for the test data at each throttle setting for each parachute. Two different integration methods were used: a polar coordinate formulation and a Cartesian coordinate formulation.

$$
\beta=\frac{1}{\mathrm{~A}} \cdot \oint_{\mathrm{A}}\left(\frac{\mathrm{u}}{\mathrm{V}_{\text {air }}}\right)^{2} \mathrm{dA}
$$

\section{A. Polar Coordinate Formulation}

For cases where the parachute is centered along the flow axis, polar coordinates are the most convenient. Figure 8 shows the polar coordinates used to evaluate the integral. The differential area is defined from a differential radius as in Eq. 4. Substituting the differential area and the area of a circle into Eq. 3 results in Eq. 5. The expression simplifies to Eq. 6. Although this integral could be solved analytically by substituting each flow field polynomial curve fit, it was simpler to compute each factor with numerical integration.

$$
\begin{gathered}
\mathrm{dA} \approx 2 \cdot \pi \cdot \mathrm{r} \cdot \mathrm{dr} \\
\beta=\frac{1}{\pi \cdot\left(\frac{\mathrm{D}_{\mathrm{p}}}{2}\right)^{2}} \cdot \int_{\mathrm{r}=0}^{\mathrm{D}=\frac{\mathrm{D}_{\mathrm{p}}}{2}}\left(\frac{\mathrm{u}}{\mathrm{V}_{\text {air }}}\right)^{2} 2 \cdot \pi \cdot \mathrm{r} \cdot \mathrm{dr}
\end{gathered}
$$

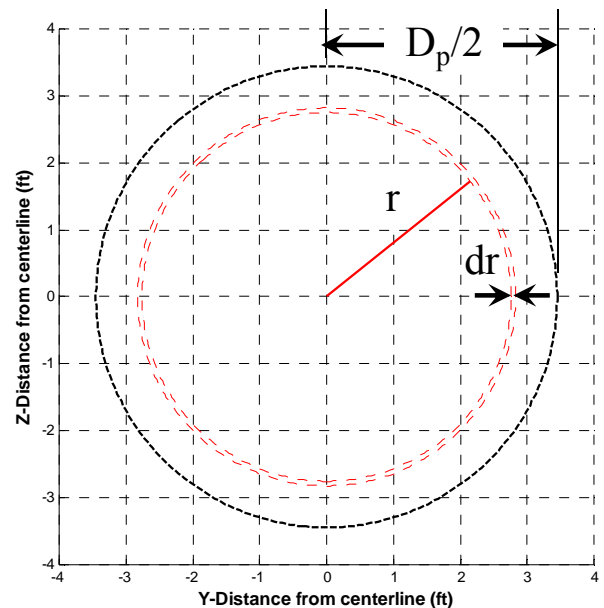

Figure 8. Differential flow area using polar coordinates.

$$
\beta=\frac{8}{\mathrm{D}_{\mathrm{p}}{ }^{2} \cdot \mathrm{V}_{\mathrm{air}}{ }^{2}} \cdot \int_{\mathrm{r}=0}^{\mathrm{r}=\frac{\mathrm{D}_{\mathrm{p}}}{2}} \mathrm{u}^{2} \cdot \mathrm{r} \cdot \mathrm{dr}
$$

The resulting equivalent velocity for both size parachutes is compared with the flow field at the penultimate throttle setting in Figure 9. Because the FBCP is the smallest parachute, its equivalent airspeed is higher than that for 
the larger parachutes. This is because the smaller parachute sees more of a concentrated central core flow. However, this result is only valid during the brief times when the FBCP is aligned with the centerline.

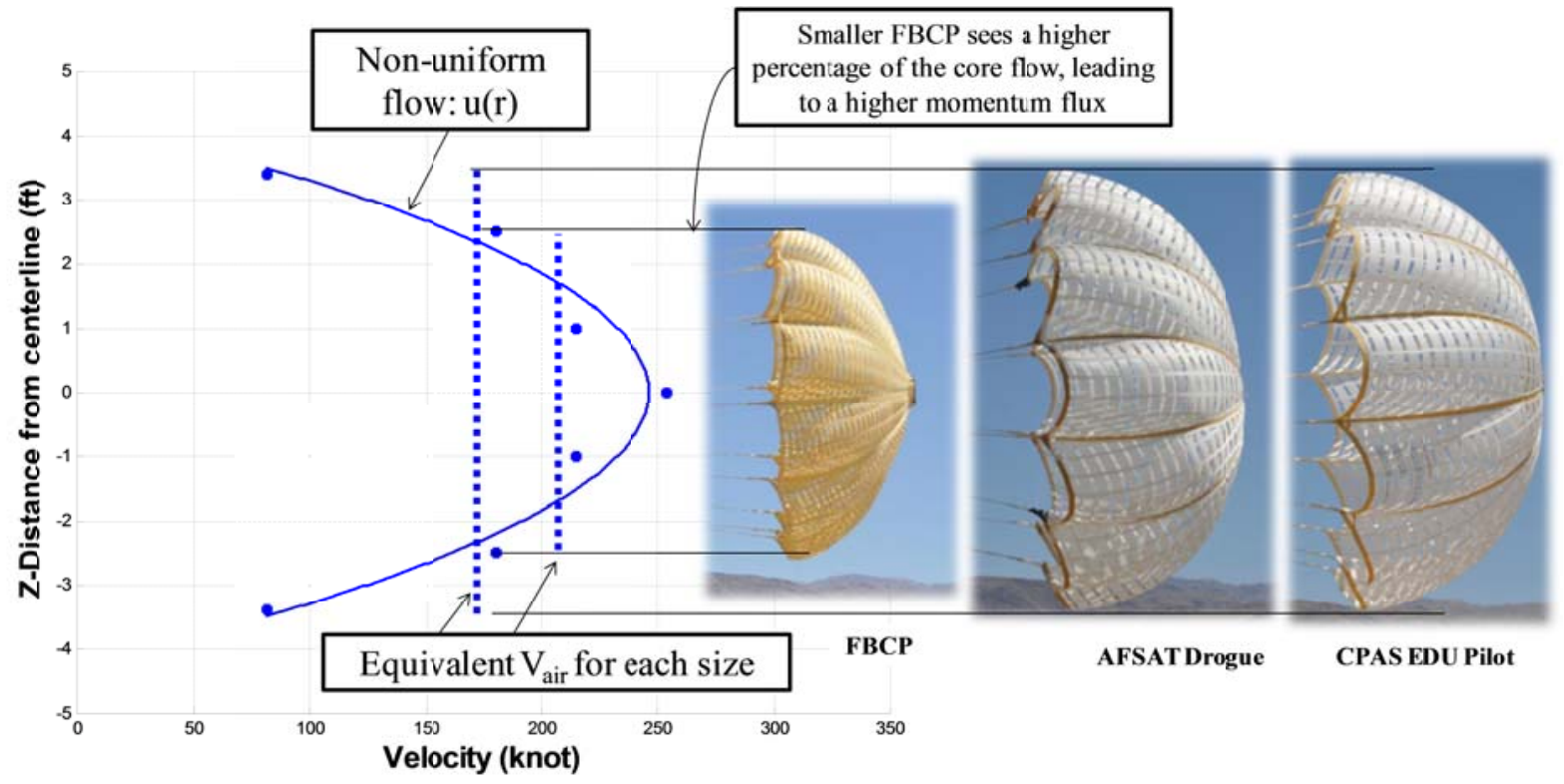

Figure 9. Resulting non-uniform flow and equivalent flow velocity using polar coordinates.

\section{B. Cartesian Coordinate Formulation}

The polar form of this equation is only useful if the parachute is centered along the nozzle centerline. However, the FBCP was noticeably less stable than the other parachutes, and oscillated about the centerline. To account for a given off-axis angle, $\theta$, the momentum flux was also computed using Cartesian coordinates. The off-axis angle is shown in Figure 10. In this case, the differential area is the differential width multiplied by differential height, as in Eq. 7, and $\beta$ is computed according to Eq. 8

$$
\beta=\frac{1}{\pi \cdot\left(\frac{D_{p}}{2}\right)^{2}} \cdot \int_{z=\frac{D_{p}}{2}}^{d A=\frac{D_{p}}{2}} \int_{y=\frac{D_{p}}{2}}^{2}\left(\frac{u}{V_{a i r}}\right)^{2} d y \cdot d z
$$

To evaluate this integral, a Cartesian mesh is established and the equation is applied only at points where the skirt is projected. This is illustrated in Figure 11. 

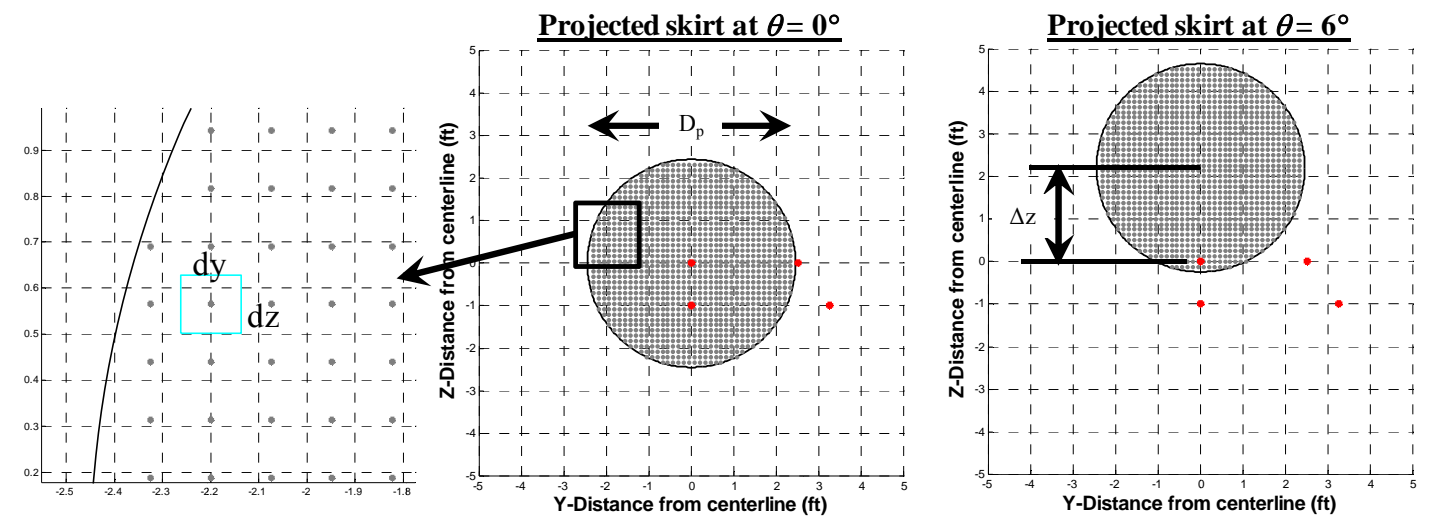

Figure 11. Sample Cartesian meshes to evaluate momentum flux correction factor.

Sample projected flows are shown for four offset angles in Figure 12. The equivalent flows at the $\theta=0^{\circ}$ condition were similar to the results using the polar coordinate system. As the distance moves away from the centerline, the velocity curve fits will eventually have negative flow rates, which are not physically possible. Therefore, any reversed flows are bounded at zero.
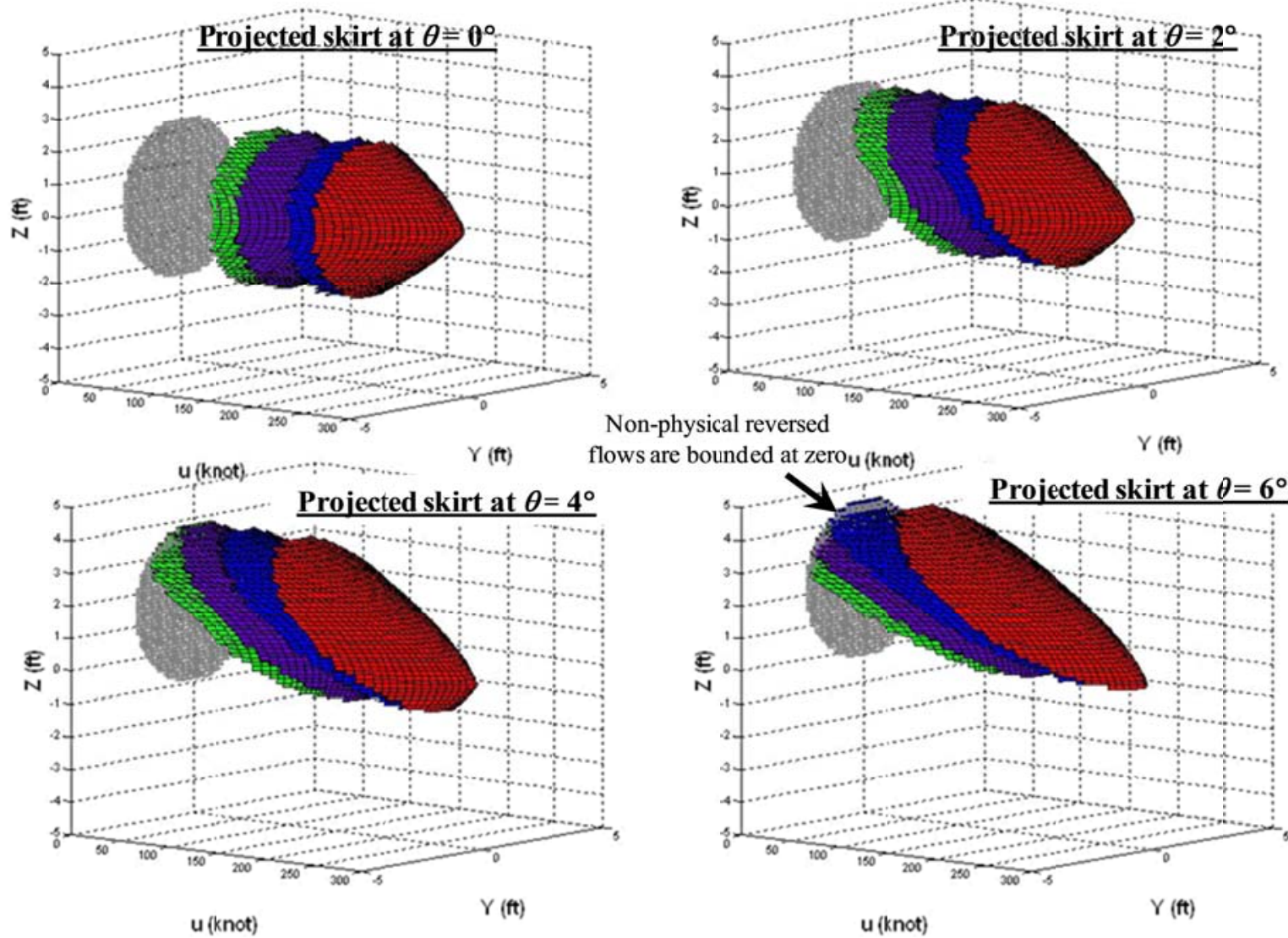

Non-physical reversed
flows are bounded at zero $\mathrm{u}(\mathrm{knot})$

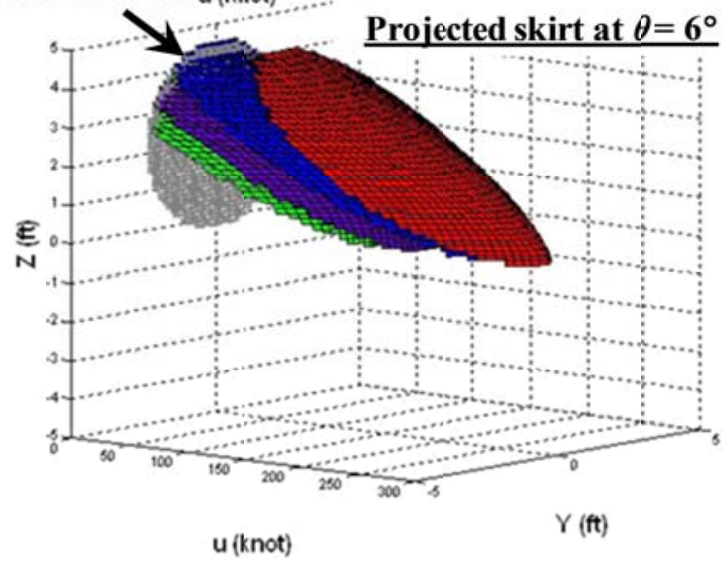

Figure 12. Resulting non-uniform projected flows at various off-axis angles using Cartesian coordinates. 


\section{Load Measurements}

Parachute load measurements were taken by a strain link rated to $10 \mathrm{k}$ lbf with approximately $10 \mathrm{lbf}$ resolution. Data were recorded at $100 \mathrm{~Hz}$.

\section{A. AFSAT Drogue Parachute}

The AFSAT Drogue parachute was the first parachute tested because it had known performance. The flow at the nozzle and the resulting loads trace is shown in Figure 13.
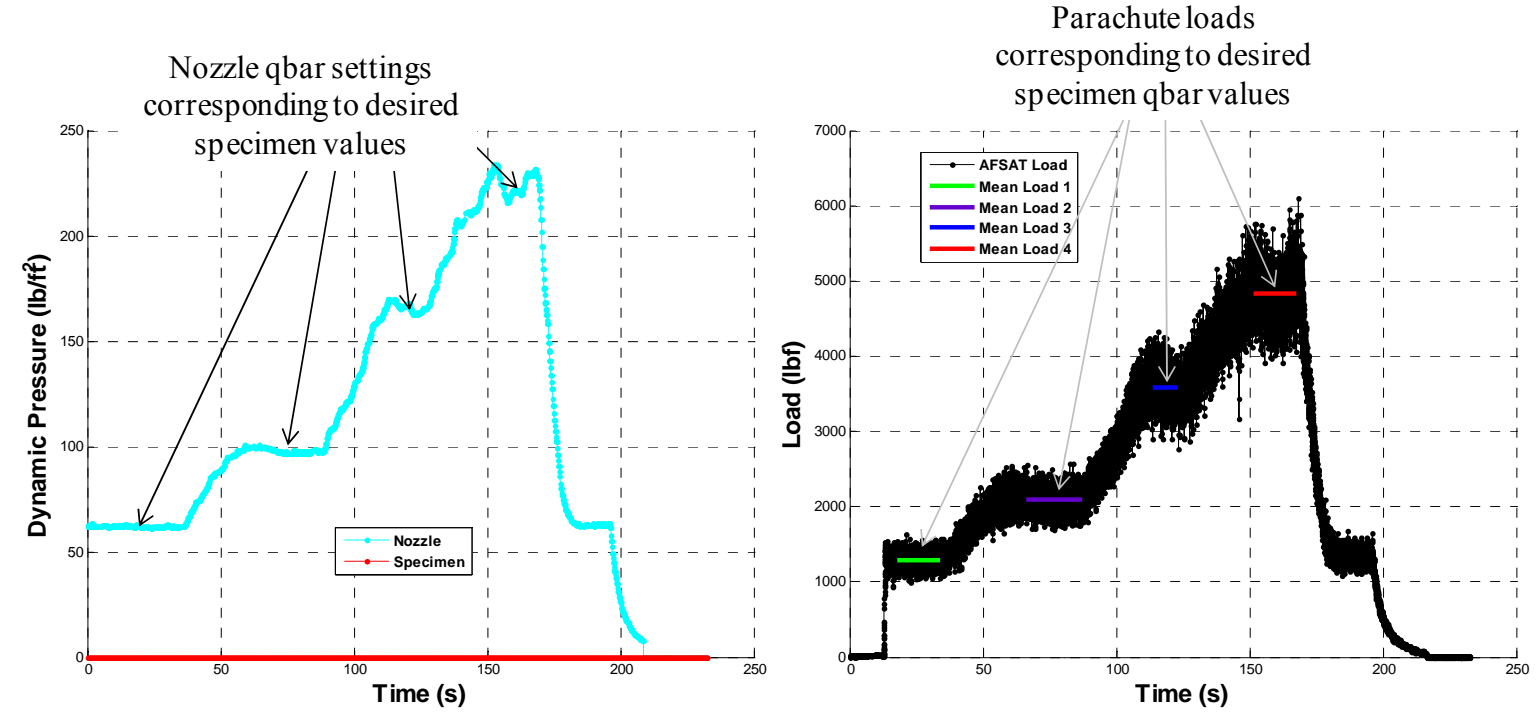

Figure 13. Measured nozzle dynamic pressure (left) and AFSAT Drogue load (right).

\section{B. EDU Forward Bay Cover Parachute}

Post-test inspection revealed that the confluence keeper on the FBCP failed during the test. This is not a significant concern for the operational use of the FBCP in flight because the length of time during which the FBCP will be active in flight is much shorter than the duration of the test and the failure mode is not detrimental to the purpose of the parachute. Increasing the suspension line convergence angle will tend to increase the projected area and drag force.
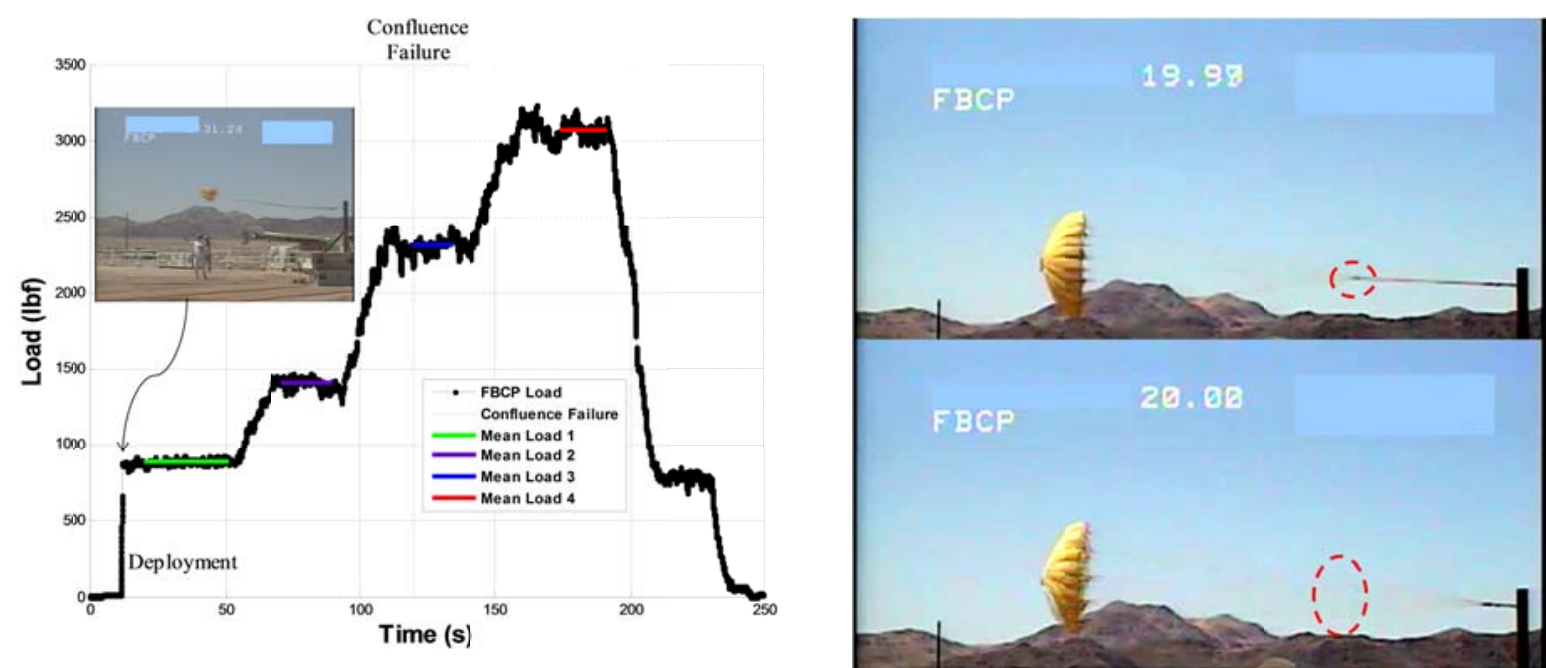

Figure 14. FBCP load trace.

American Institute of Aeronautics and Astronautics 
The FBCP oscillated significantly in all radial directions more than the other parachutes during the test. Several methods were considered to account for the oscillation in the drag coefficient calculation. The JSC-KX Image Science \& Analysis Group tracked the FBCP vent center coordinates in a longitudinal video. A small amount of tracking data is superimposed in Figure 15, demonstrating the FBCP moved back-and-forth with some coning motion.

Correlating the load trace with the instantaneous off-angle observed in video is problematic due to the slow frame rate (30 frames per second) and low resolution of the standard definition (SD) video. Also, while the video is time-coded, the load data did not have an absolute time stamp, making synchronization difficult.

A dual-exposure image in Figure 16 shows the extent of the oscillation, estimated to be about five degrees from photographic analysis. Because the flow velocity tapers off from the centerline, the effective flow velocity at this position is significantly less than the core flow, as shown in Figure 17.

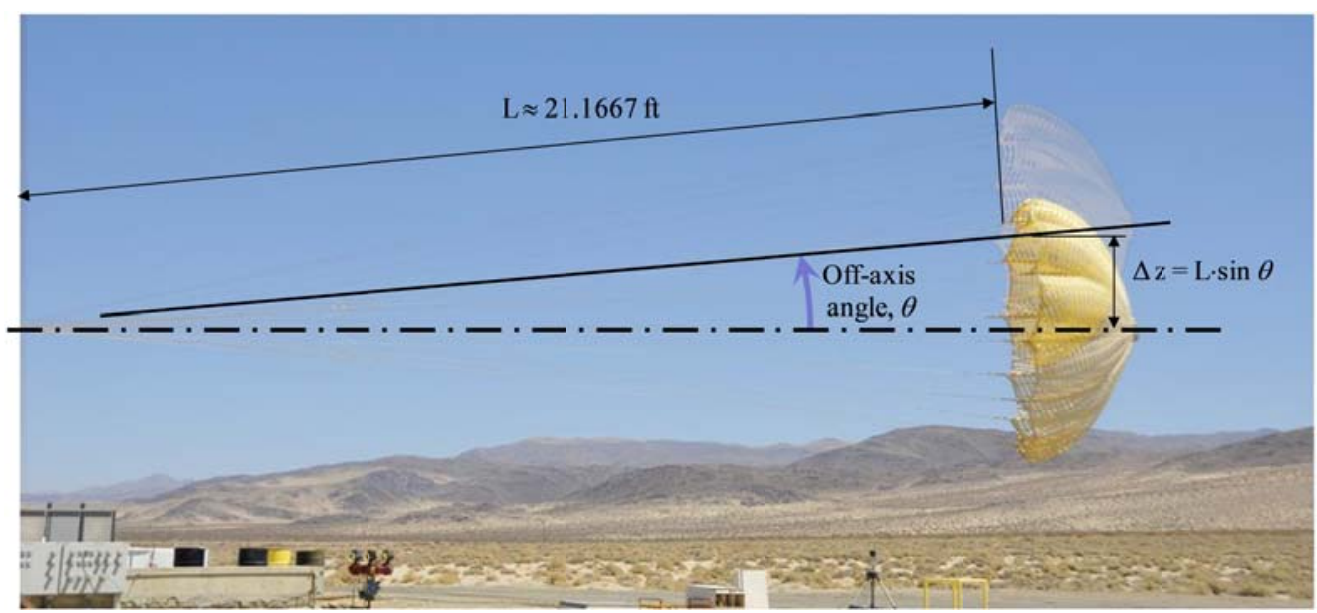

Figure 16. Dual-exposure of FBCP off-axis oscillation. 


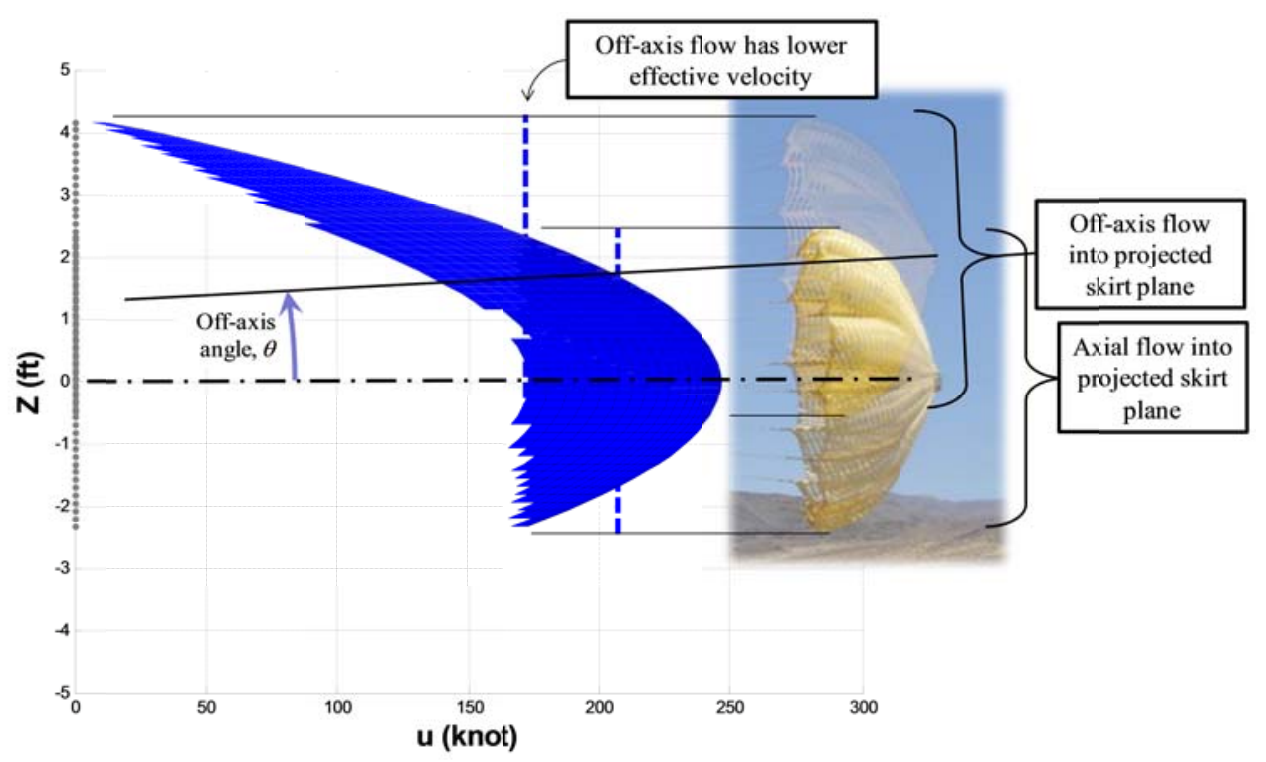

Figure 17. FBCP effective flow velocity comparison of axial flow and largest off-axis angle.

Another method considered was to assume that the maximum loads would be encountered when the FBCP was along the centerline and the minimum loads would occur at the farthest off-axis angle. However, a close inspection of the video and data indicate that the observed oscillation frequency was considerably faster than the variation in the load trace. A typical oscillation period of about one second is shown in Figure 18. However, the tracking data showed that the FBCP had oscillated about ten times in that period. Only small load variations on the order of the measurement uncertainty occurred during a typical visible cycle. Therefore, variations in the loads data are most likely caused by perturbations in the HIVAS throttle setting and flow output.

Knowing the data varied with time, it was desired to compute a flow corresponding to the "average" off-axis angle without the efforts and uncertainty of a time-varying video analysis. The FBCP oscillation can be modeled as a repeating sinusoidal function. The absolute amplitude was assumed to be five degrees, based on the side-view photograph. The time average value for halfperiod of a sinusoid function is the amplitude multiplied by $2 / \pi$. Therefore, the average flow velocity was computed for an off-axis angle is $5^{\circ} \cdot 2 / \pi \approx 3.18^{\circ}$. Assuming a large number of periods occur during the averaging window, this result is independent of the oscillation frequency. The effective flow at this angle was then used with the timeaveraged load data to compute drag coefficient.

\section{EDU Pilot Parachute}

As with the FBCP, the confluence keeper on the Pilot parachute failed during the test. Again, this was not a significant concern to the program for the same reasons. The load trace is shown in Figure 19. The confluence failure is shown on video captures and noted on the loads trace. 


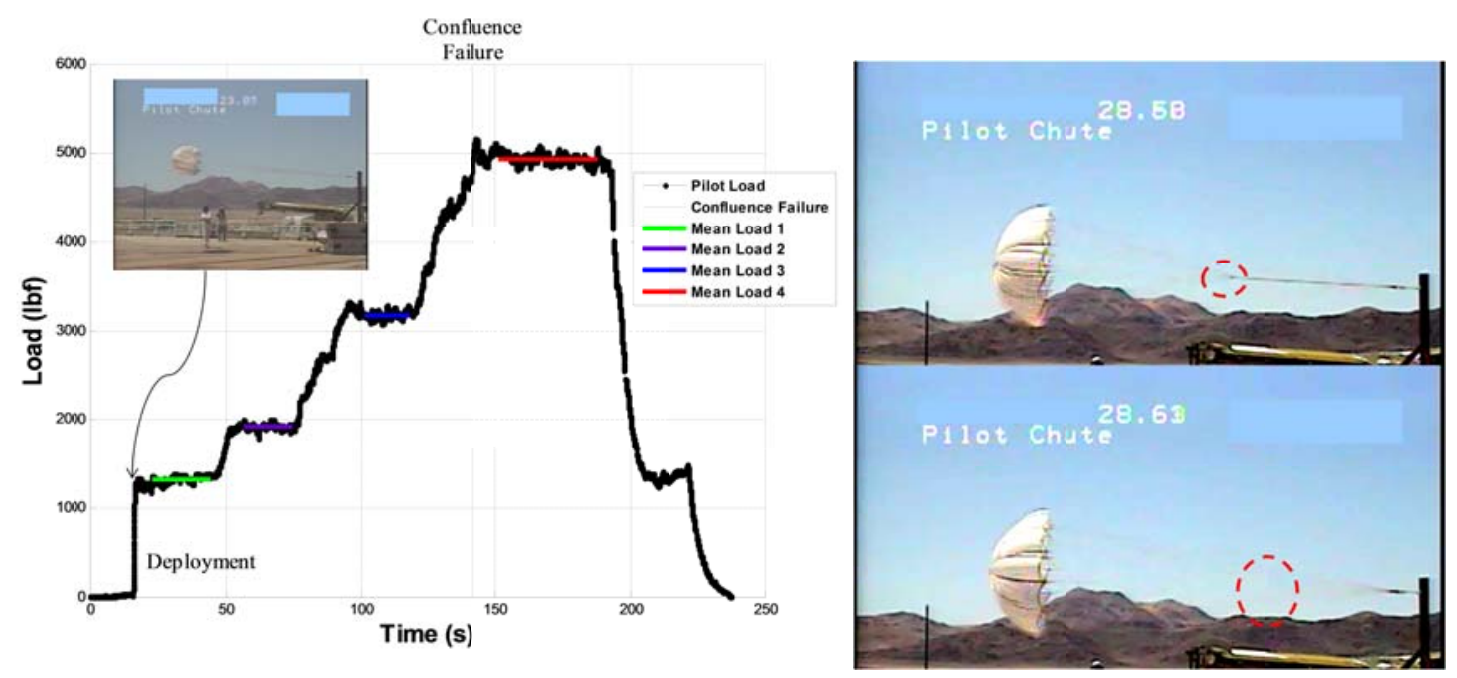

Figure 19. Pilot parachute load trace.

\section{Drag Coefficient Calculations.}

Real-time drag coefficient calculations during the test did not consider the non-uniform flow and the results were unreasonably low. Post-test analysis was necessary to properly normalize the drag with the momentum-flux corrected velocity.

A further correction was applied to the load data to account for the manual adjustment in the HIVAS throttle setting. A scaling factor was computed at each throttle setting by dividing the measured nozzle dynamic pressure with the corresponding nozzle dynamic pressure during the calibration runs. This assumes a linear relationship between the dynamic pressure at the nozzle and the dynamic pressure at the specimen.

\section{A. AFSAT Drogue Parachute}

The AFSAT results are summarized in Table 1. Each of the four throttle settings are listed in a separate column. The readings before flow corrections are shown in red. Because the canopy was relatively stable, the airspeed corrections were made assuming axial flow using the polar coordinate formulation. Scaling the loads based on the measured nozzle readings resulted in only a small adjustment to each mean load.

The computed drag coefficients are notably higher at lower throttle settings than the later results. Airborne Systems provided a drag coefficient of about 0.55 from previous AFSAT Drogue test data. Therefore, the computed Drogue coefficient from HIVAS of 0.606 is about $10 \%$ higher than expected.

Table 1. AFSAT Drogue Parachute Results with Axial Flow

\begin{tabular}{|c|c|c|c|c|}
\hline Mean Airspeed, $\mathrm{V}_{\text {air }}(\mathrm{knot})$ & 131.3 & 165.3 & 214.8 & 250.1 \\
\hline Corrected Airspeed, $\mathrm{V}_{\text {air }}(\mathrm{knot})$ & 93.0 & 121.1 & 172.5 & 200.8 \\
\hline Corrected Airspeed, $\mathrm{V}_{\text {air }}(\mathrm{ft} / \mathrm{s})$ & 157.0 & 204.4 & 291.1 & 338.9 \\
\hline Mean qbar $\left(\mathrm{lb} / \mathrm{ft}^{2}\right)$ & 51.9 & 81.7 & 135.3 & 180.0 \\
\hline Corrected qbar $\left(\mathrm{lb} / \mathrm{ft}^{2}\right)$ & 25.6 & 43.1 & 86.2 & 115.2 \\
\hline Mean Load, F $(\mathrm{lbf})$ & 1,295 & 2,088 & 3,578 & 4,836 \\
\hline Scaled Mean Load, F (lbf) & 1,268 & 2,139 & 3,701 & 4,901 \\
\hline Drag Coefficient, $\mathrm{C}_{\mathrm{D}}$ & $\mathbf{0 . 6 4 9}$ & $\mathbf{0 . 6 5 2}$ & $\mathbf{0 . 5 6 3}$ & $\mathbf{0 . 5 5 8}$ \\
\hline Average Drag Coefficient, $\mathbf{C}_{\mathbf{D}}$ & \multicolumn{5}{|c|}{$\mathbf{0 0 6}$} \\
\hline
\end{tabular}

\section{B. EDU Forward Bay Cover Parachute}

The initial computation of the FBCP drag coefficient assumed the axial flow formulation, with results shown in Table 2. The last two throttle settings occurred after the confluence failure. One would expect that the loss of the confluence would slightly open the canopy, resulting in a higher drag coefficient, but the computed drag coefficient actually dropped. 
Table 2. EDU Forward Bay Cover Parachute Results with Axial Flow

\begin{tabular}{|c|c|c|c|c|}
\hline Mean Airspeed, $\mathrm{V}_{\text {air }}(\mathrm{knot})$ & 131.3 & 165.3 & 214.8 & 250.1 \\
\hline Corrected Airspeed, $\mathrm{V}_{\text {air }}(\mathrm{knot})$ & 121.8 & 151.2 & 207.1 & 232.4 \\
\hline Corrected Airspeed, $\mathrm{V}_{\text {air }}(\mathrm{ft} / \mathrm{s})$ & 205.5 & 255.1 & 349.6 & 392.2 \\
\hline Mean qbar $\left(\mathrm{lb} / \mathrm{ft}^{2}\right)$ & 51.9 & 81.7 & 135.3 & 180.0 \\
\hline Corrected qbar (lb/ft $\left.{ }^{2}\right)$ & 43.7 & 66.7 & 123.2 & 152.8 \\
\hline Mean Load, F (lbf) & 889 & 1,409 & 2,309 & 3,072 \\
\hline Scaled Mean Load, F (lbf) & 895 & 1,519 & 2,413 & 3,076 \\
\hline Drag Coefficient, $\mathrm{C}_{\mathrm{D}}$ & $\mathbf{0 . 5 3 2}$ & $\mathbf{0 . 5 9 2}$ & $\mathbf{0 . 5 0 9}$ & $\mathbf{0 . 5 2 3}^{*}$ \\
\hline Average Drag Coefficient, $\mathbf{C}_{\mathbf{D}}$ & \multicolumn{5}{|c|}{ *.539 After confluence failure } \\
\hline
\end{tabular}

The drag coefficient was also computed using the previously mentioned average off-axis angle of $3.18^{\circ}$ with results listed in Table 3. Because the effective flow is reduced, the drag coefficient is increased for the same measured drag force.

Table 3. EDU Forward Bay Cover Parachute Results with Mean Off-Axis Flow

\begin{tabular}{|c|c|c|c|c|}
\hline Corrected Airspeed, $\mathrm{V}_{\text {air }}(\mathrm{knot})$ & 110.0 & 138.5 & 192.0 & 219.2 \\
\hline Corrected Airspeed, $\mathrm{V}_{\text {air }}(\mathrm{ft} / \mathrm{s})$ & 185.7 & 233.8 & 324.1 & 369.9 \\
\hline Corrected qbar $\left(\mathrm{lb} / \mathrm{ft}^{2}\right)$ & 35.7 & 56.0 & 105.9 & 135.9 \\
\hline Scaled Mean Load, F (lbf) & 895 & 1,519 & 2,413 & 3,076 \\
\hline Drag Coefficient, $\mathrm{C}_{\mathrm{D}}$ & $\mathbf{0 . 6 5 2}$ & $\mathbf{0 . 7 0 5}$ & $\mathbf{0 . 5 9 2}$ & $\mathbf{0 . 5 8 8}^{*}$ \\
\hline Average Drag Coefficient, $\mathbf{C}_{\mathbf{D}}$ & $\mathbf{0 . 6 3 4}$ \\
\hline
\end{tabular}

*After confluence failure

The drag performance of all CPAS parachutes are documented as drag area probability distributions based on flight test data in the "Engineering Development Unit Operating Modeling Parameters Version 11" (aka the "CPAS Model Memo v11"). ${ }^{9}$ These distributions are explained in Ref. 10. However, the FBCPs had not yet been flight tested as of the current model release. The FBCP design is similar to the CPAS Drogue design and both types of parachutes have a suspension line length ratio $\left(\mathrm{L}_{\mathrm{s}} / \mathrm{D}_{\mathrm{o}}\right)$ of 2.0. Therefore, FBCP drag area distribution was determined by scaling full open EDU Drogue drag area data according to Eq. 9. The scaled Drogue data were used to define the drag area probability distribution published in Model Memo v11.

$$
\left(\mathrm{C}_{\mathrm{D}} \mathrm{S}\right)_{\mathrm{FBCP}}=\left(\mathrm{C}_{\mathrm{D}} \mathrm{S}\right)_{\text {Drogue }} \cdot \frac{\left(\mathrm{S}_{\mathrm{o}}\right)_{\mathrm{FBCP}}}{\left(\mathrm{S}_{\mathrm{o}}\right)_{\text {Drogue }}}=\left(\mathrm{C}_{\mathrm{D}} \mathrm{S}\right)_{\text {Drogue }} \cdot \frac{\left(\mathrm{D}_{\mathrm{o}}\right)_{\mathrm{FBCP}}^{2}}{\left(\mathrm{D}_{\mathrm{o}}\right)_{\text {Drogue }}^{2}}
$$

The distribution of scaled EDU Drogue test data is shown in blue in Figure 20. The HIVAS data from both methods have been appended to the histogram to evaluate how including HIVAS data would affect the distribution. The axial method FBCP results were generally lower than the scaled Drogue data and the off-axis results were higher. Due to uncertainties in the test data, a decision was made to include data from all three sources to generate the best fit normal (Gaussian) distribution. This results in a distribution most likely to encompass the true performance. The "nominal" value is the median of all the data. Because the FBCP has only half the number of gores as a CPAS Drogue (12 vs. 24), the FBCP was expected to be less efficient than the scaled Drogue data. However, the scaled Drogue data were obtained in the presence of a test vehicle forebody drag, while HIVAS flow is not significantly obstructed. These effects may have counteracted each other such that the composite distribution has a similar mean value to the published distribution. The addition of the HIVAS data has widened the distribution, increasing the standard deviation by about $35 \%$. This distribution will be revised as planned flight test data becomes available. 


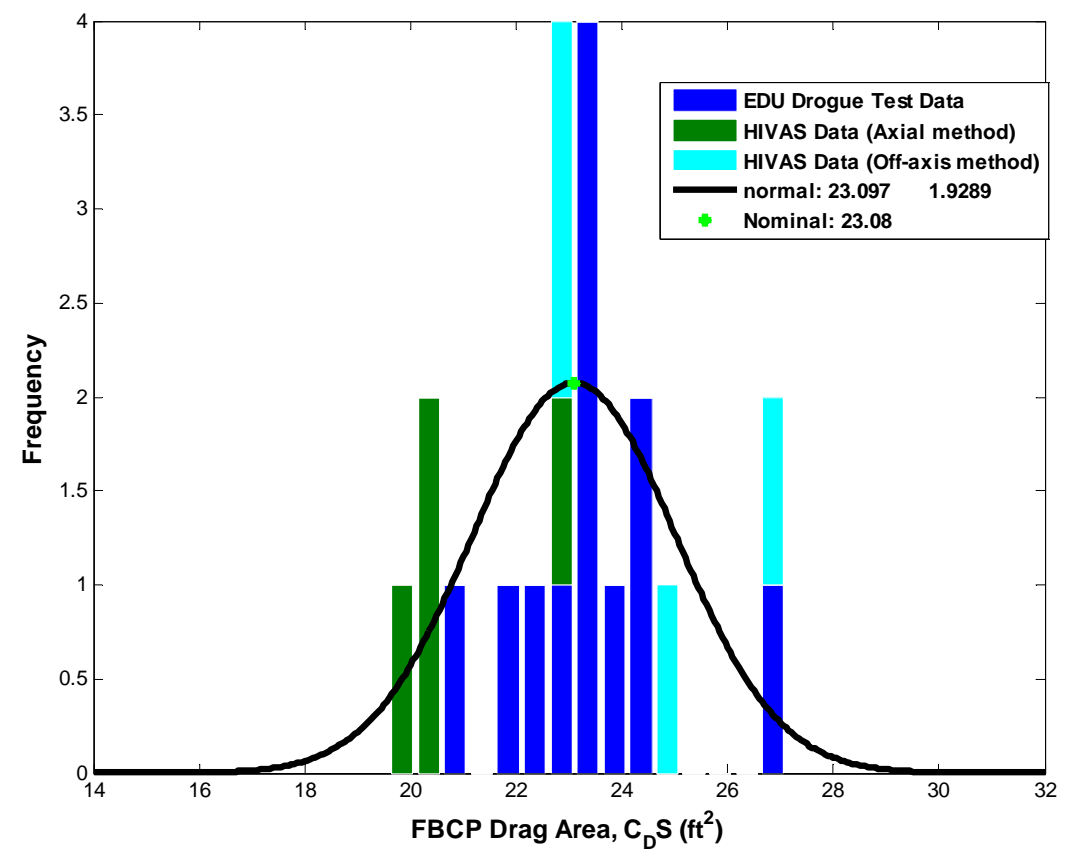

Figure 20. Comparison of expected FBCP drag area with HIVAS results.

\section{EDU Pilot Parachute}

The Pilot parachute did not exhibit significant oscillations, so the drag coefficients listed in Table 4 were computed using the axial flow method. The drag coefficient fell with increasing flow and then rose after the confluence failed (the last column).

Table 4. EDU Pilot Parachute Results with Axial Flow

\begin{tabular}{|c|c|c|c|c|}
\hline Mean Airspeed, $\mathrm{V}_{\text {air }}(\mathrm{knot})$ & 131.3 & 165.3 & 214.8 & 250.1 \\
\hline Corrected Airspeed, $\mathrm{V}_{\text {air }}(\mathrm{knot})$ & 93.0 & 121.1 & 172.5 & 200.8 \\
\hline Corrected Airspeed, $\mathrm{V}_{\text {air }}(\mathrm{ft} / \mathrm{s})$ & 157.0 & 204.4 & 291.1 & 338.9 \\
\hline Mean qbar $\left(\mathrm{lb} / \mathrm{ft}^{2}\right)$ & 51.9 & 81.7 & 135.3 & 180.0 \\
\hline Corrected qbar $\left(\mathrm{lb} / \mathrm{ft}^{2}\right)$ & 25.3 & 42.8 & 85.4 & 113.8 \\
\hline Mean Load, $\mathrm{F}(\mathrm{lbf})$ & 1,326 & 1,919 & 3,176 & 4,939 \\
\hline Scaled Mean Load, F (lbf) & 1,317 & 1,816 & 2,999 & 4,835 \\
\hline Drag Coefficient, $\mathrm{C}_{\mathrm{D}}$ & $\mathbf{0 . 6 8 7}$ & $\mathbf{0 . 5 8 9}$ & $\mathbf{0 . 4 8 8}$ & $\mathbf{0 . 5 6 9}^{*}$ \\
\hline Average Drag Coefficient, $\mathbf{C}_{\mathbf{D}}$ & \multicolumn{5}{|c|}{.583 } \\
\hline
\end{tabular}

The EDU Pilot parachutes have been successfully used in all EDU flight tests. However, only limited data has been acquired and direct measurements of drag area may not be possible in flight because the each Pilot parachute becomes unloaded as its corresponding Main parachute deploys. The Pilot parachute conical ribbon design is similar to a smaller version of the CPAS Drogue design. The EDU Pilot design has an $\mathrm{L}_{\mathrm{s}} / \mathrm{D}_{\mathrm{o}}$ ratio of 1.15 . Therefore, the Pilot drag area distribution was determined by scaling full open CPAS Gen I \& II Drogue data $\left(\mathrm{L}_{\mathrm{s}} / \mathrm{D}_{\mathrm{o}}=1.5\right)$ rather than the EDU Drogue data $\left(\mathrm{L}_{\mathrm{s}} / \mathrm{D}_{\mathrm{o}}=2.0\right)$. The data were scaled according to Eq. 10.

$$
\left(C_{D} S\right)_{\text {Pilot }}=\left(C_{D} S\right)_{\text {Drogue }} \cdot \frac{\left(S_{o}\right)_{\text {Pilot }}}{\left(S_{o}\right)_{\text {Drogue }}}=\left(C_{D} S\right)_{\text {Drogue }} \cdot \frac{\left(D_{0}\right)_{\text {Pilot }}^{2}}{\left(D_{o}\right)_{\text {Drogue }}^{2}}
$$


Only a limited set of four clean-wake Drogue data points were available with the smaller $\mathrm{L}_{\mathrm{s}} / \mathrm{D}_{\mathrm{o}}$ ratio: DDT-1, DDT-2, DDT-3, and a 10\% scale Texas A\&M University Wind Tunnel Test. ${ }^{11}$ All of these tests were considered to be in a "clean" wake. The resulting distribution published in CPAS Model Memo v11 did not have a central tendency, so a uniform dispersion was used. However, the additional data from HIVAS appears to show a central tendency, so a normal distribution was fit to the composite data, as shown in Figure 21. The EDU Pilot parachute also has half the number of gores as the CPAS Drogue, so some loss of drag efficiency was expected.

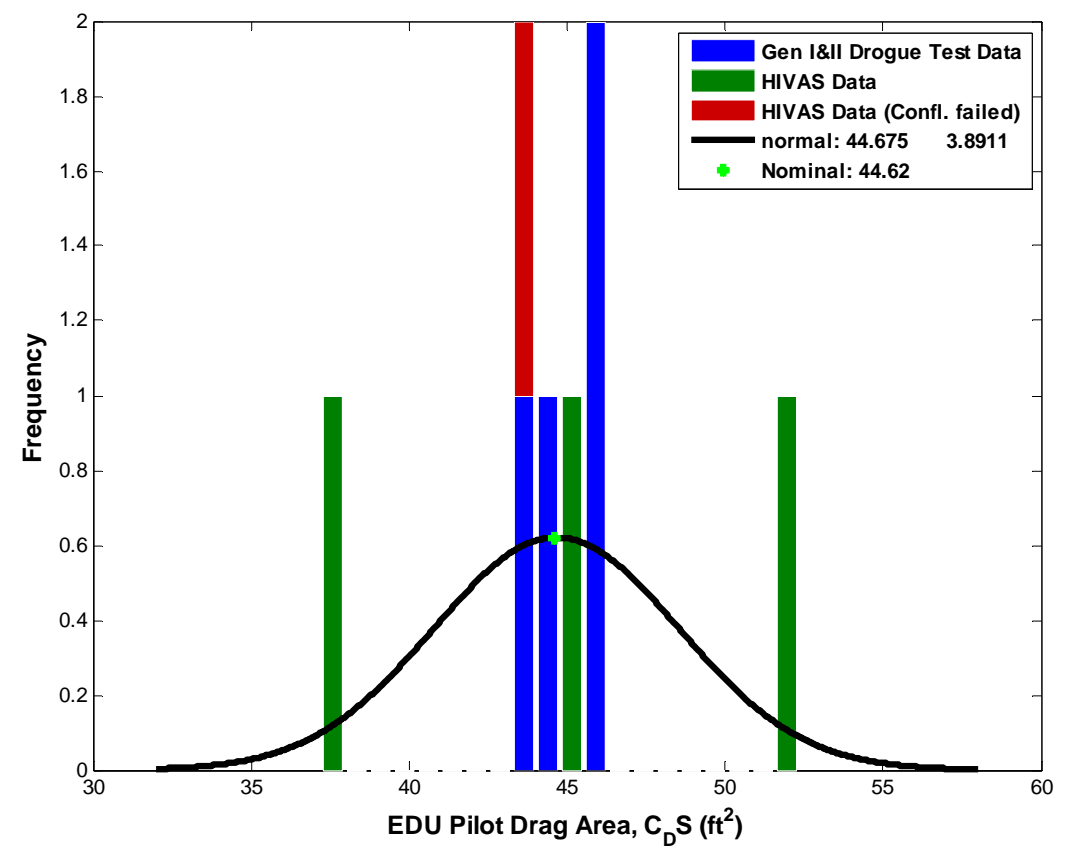

Figure 21. Comparison of expected Pilot parachute drag area with HIVAS axial flow results.

\section{Operational Lessons Learned}

Some procedural issues were encountered during this test. The initial method to deploy the parachute into the airflow by pulling a line resulted in a premature deployment and HIVAS was shut down. A simpler method of manually tossing each canopy into the flow was successful. During the second run, the block holding the parachute began to move, despite being several times heavier than the force generated by the test parachute, and again the test was temporarily suspended. The parachute drag had caused a lever-arm effect on the block, tipping it enough to reduce the surface area until friction was no longer enough to hold it in place. This was mitigated by adding a second block to the test stand and securing the assembly to rails embedded to the deck with chains.

\section{Conclusion}

The HIVAS facility at China Lake was used in lieu of flight test to determine parachute drag performance of two small CPAS parachutes. Another parachute with known performance was tested as a control.

HIVAS produces a non-uniform flow, which was assumed to be axisymmetric for this analysis, though limited flow survey maps are available at certain settings and distances. Effective flow velocities at each throttle setting were computed for each size parachute using the definition of the momentum flux factor. The FBCP was not as stable as the other parachutes, requiring additional calculations of the projected flow at an off-axis angle.

The computed drag coefficient on the control AFSAT Drogue was about 10\% higher than previous data, which may indicate an under-estimation of the effective flow velocity. Steady-state data from HIVAS compared favorably to previously estimated parachute performance based on scaled data from analogous CPAS parachutes. Inclusion of the HIVAS data with previous data increases each standard deviation, making the model more likely to encompass actual performance in flight. The resulting drag area distributions will be included in the next version of the CPAS Model Memo. 
The range of effective dynamic pressure tested was similar to the extent of the CPAS deployment envelopes, seen in Figure 22. However, HIVAS is limited by its ambient conditions in the Mach number and pressure altitude available. Larger parachutes cannot be tested effectively due to the flow decay from the center core and ground effects. Deployment was not representative to flight, so inflation parameters could not be obtained.

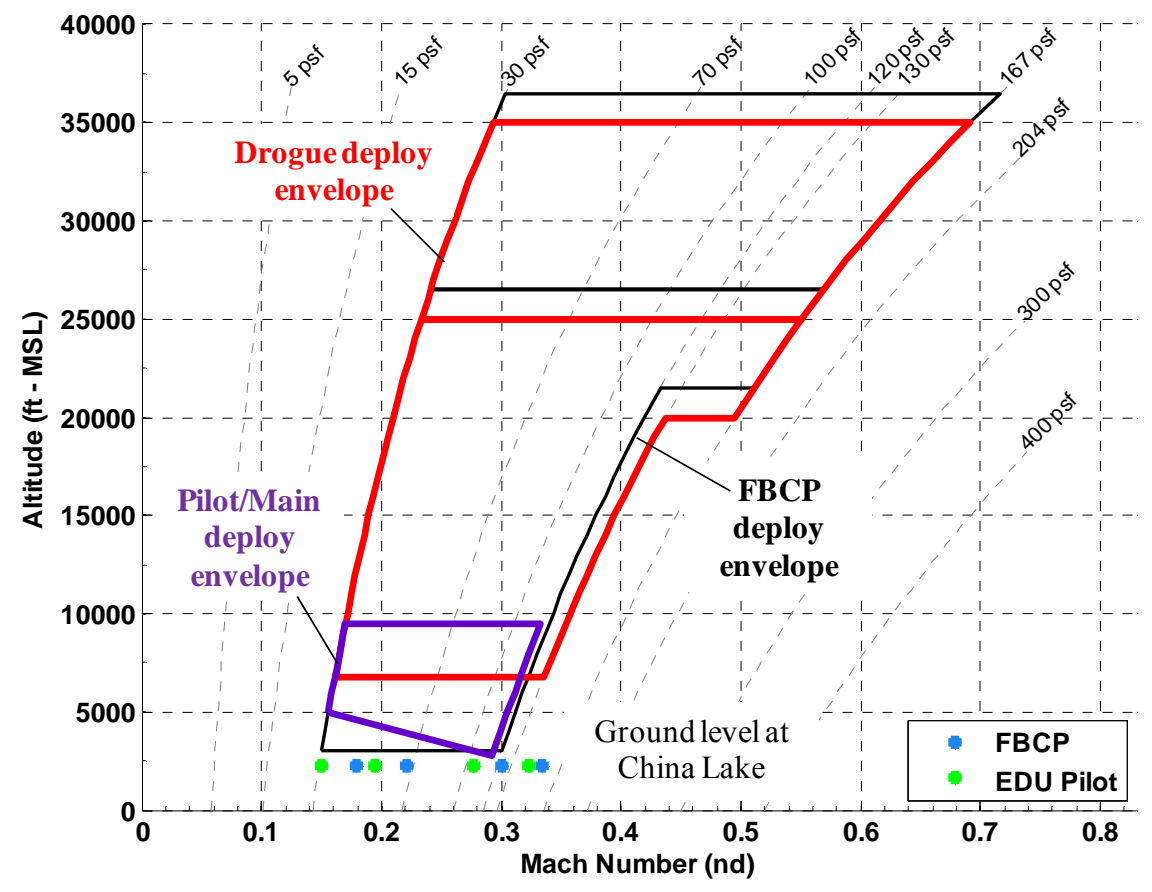

Figure 22. Effective HIVAS flow velocity compared to CPAS deployment envelopes.

Overall, HIVAS provided valuable data to the CPAS program with a much lower cost and complexity relative to flight testing.

\section{Acknowledgments}

The authors wish to acknowledge the personnel at the China Lake Weapons Survivability Lab who operated HIVAS for their efforts during this test. Special thanks to Matt Zwicker of Airborne Systems for aiding the planning, execution, and analysis of the test.

\section{References}

${ }^{1}$ Ray, E. S. and Morris, A. L., "Challenges of CPAS Flight Testing," $21^{\text {st }}$ AIAA Aerodynamics Decelerator Systems Technology Conference, Dublin, Ireland, May 2011, AIAA paper 2011-2557.

${ }^{2}$ Olmstead, R., Morris, A. L., Bledsoe, K. B., and Englert, M., "Overview of the Crew Exploration Vehicle Parachute Assembly System (CPAS) Generation I Drogue and Pilot Development Test Results," $20^{\text {th }}$ AIAA Aerodynamics Decelerator Systems Technology Conference, Seattle, Washington, May 2009, AIAA paper 2009-2939.

${ }^{3}$ Whitmore, S. A., Hennings, E. J., "Design of a Passively Reefed, Collapsible Drogue Parachute System," Journal of Aircraft, Vol. 44, No. 6, November-December 2007, pp. 1793-1804.

${ }^{4}$ Hennings, E. J., Wolf, D., Whitmore, S. A., and Jensen, S., W., "Design and Testing of a Collapsible Drogue Parachute for the X-37 Vehicle," $18^{\text {th }}$ AIAA Aerodynamics Decelerator Systems Technology Conference, 2005, AIAA paper 2005-1660.

${ }^{5}$ Whitmore, S. A., et al., "Development and Testing of a Drogue Parachute System for X-37 ALTV / B-52H Separation," 42 ${ }^{\text {nd }}$ AIAA Aerospace Sciences Meeting and Exhibit, Reno, Nevada, 5-8 January 2004, AIAA paper 2004-873. 
${ }^{6}$ Farhall, R. J., Sinclair, R. J., and Meyer, D. A., "Design and Testing of the BQM-167A Parachute Recovery System," $19^{\text {th }}$ AIAA Aerodynamics Decelerator Systems Technology Conference, Williamsburg, Virginia, May 2007, AIAA paper 2007-2512.

${ }^{7}$ Knacke, T. W., Parachute Recovery Systems Design Manual, NWC TP 6575, $1^{\text {st }}$ ed., Para Publishing, Santa Barbara, California, 1992.

${ }^{8}$ White, F. M, Fluid Mechanics, $5^{\text {th }}$ ed., McGraw-Hill, Boston, Chap. 3.

${ }^{9}$ Ray, E. S., et al., Capsule Parachute Assembly System (CPAS) Engineering Development Unit Operating Modeling Parameters Version 11, JSC 65914 Rev F, ESCG-8400-CPAS-10-CPAS-MEMO-0069 Rev F, November 2012, Jacobs Sverdrup Engineering and Science Contract Group.

${ }^{10}$ Romero, L. M., Varela, J., “Application of Statistically Derived CPAS Parachute Parameters," $22^{\text {nd }}$ AIAA Aerodynamic Decelerator Systems Technology Conference, Daytona Beach, Florida, March 2013 (submitted for publication).

11 Sengupta, A., et al., "Subscale Test Program for the Orion Conical Ribbon Drogue Parachute," $21^{\text {st }}$ AIAA Aerodynamic Decelerator Systems Technology Conference, Dublin, Ireland, May 2011, AIAA paper 2011-2509. 